\title{
Parental Characteristics Have a Larger Effect on Children's Health Behaviour than Their Body Weight
}

\author{
Clemens Drenowatz ${ }^{a, b} \quad$ Nanette Erkelenz ${ }^{a} \quad$ Olivia Wartha ${ }^{a, c}$ \\ Susanne Brandstetter ${ }^{a, c}$ Jürgen M. Steinacker ${ }^{a}$ on behalf of the \\ URMEL-ICE Study Group \\ a Division of Sport and Rehabilitation Medicine, Ulm University Medical Centre, Ulm, \\ Germany; ${ }^{b}$ Department of Exercise Science, University of South Carolina, Columbia, SC, \\ USA; 'Institute for Epidemiology and Preventive Medicine, University of Regensburg, \\ Regensburg, Germany
}

\section{Key Words}

Overweight $\cdot$ Sedentary behaviour $\cdot$ TV time $\cdot$ Physical activity $\cdot$ Sport · Youth

\begin{abstract}
Objective: Parents take an important role in a child's development, but there is currently limited information on parental correlates with children's health behaviour. The purpose of this study, therefore, was to examine whether parental characteristics, such as body weight, TV consumption and sport participation, affect children's body weight and health behaviour. Methods: To examine the effects of parental characteristics on children's body weight and health behaviour, baseline data of 1,118 elementary school children (7.6 \pm 0.4 years) participating in a school-based intervention in southwest Germany was used. Children's height and weight were measured and parent as well as child behaviour was assessed via questionnaire. Results: BMI percentiles of children were positively associated with parental BMI $(r=0.2, p<$ 0.01). Further, high parental TV time increased the odds for high TV time in children $\left(O R_{\text {moth- }}\right.$ er $=2.2, \mathrm{OR}_{\text {father }}=2.3$ ) and parental club sport participation increased the odds for club sport participation in children $\left(\mathrm{OR}_{\text {mother }}=1.9, \mathrm{OR}_{\text {father }}=1.7\right)$. The relationship between parental and child behaviour was stronger than the relationship between parental BMI and BMI percentiles of the child. Conclusion: These results suggest that parental behaviour and role modelling provide an important contribution to childrens' health behaviour, especially at younger ages.
\end{abstract}


Drenowatz et al.: Parental Characteristics Have a Larger Effect on Children's Health Behaviour than Their Body Weight

\section{Introduction}

The association of increased body weight with cardiovascular and metabolic disease risk as well as certain types of cancer [1,2] has led the World Health Organisation to declare overweight and obesity as one of the leading future threats to public health [3]. In addition to chronic disease risk, overweight and obesity are associated with psychological problems such as depression, reduced self-esteem and lower quality of life [4]. These individual health impairments also put a significant economic burden on the society due to increased medical costs and absenteeism [5]. As excessive weight gain has partly been attributed to a lack of physical activity (PA) and a high amount of sedentary behaviour, various intervention programmes have been introduced to address the lack of sufficient participation in PA and sport. Particularly children and adolescents have been targeted as lifestyle patterns are established at a young age and then track into adulthood [6]. Further, children and adolescents are more responsive to health promotion programmes compared to adults [7]. Nevertheless, the prevalence of overweight and obesity in children and adolescents has been increasing [8], and school-based health promotion programmes have been of limited success $[9,10]$ despite their ability to reach a large amount of children independent of their socio-economic and family background $[5,11]$.

Health behaviours in children and adolescents have been shown to be impacted by various factors [12], and the omission of the family environment may be one reason for the lack of success of school-based intervention programmes concerning a healthier lifestyle. Parents, for example, influence their children's health behaviour. They can facilitate PA by transporting children to sporting venues and providing equipment as well as access to different opportunities for an active lifestyle $[13,14]$. Especially in younger children, parents may also function as role model for their children and shared engagement of parents with their children in PA or sedentary behaviours could affect a child's behaviour $[13,15]$. Furthermore there is a relation between parenting style and health behaviour among children $[16,17]$. As first characterized by Baumrind [18] and later modified by Maccoby and Martin [19], four classic parenting styles are known, each associated with different patterns of development outcomes. Research on the association between specific parenting styles, parental characteristics and child health behaviours, however, is still limited and inconsistent [13], particularly in children, as most studies focused on associations of parental behaviour and their offspring in adolescents rather than children [12]. The purpose of this study, therefore, was to examine the association between parental and their offspring's body weight as well as sedentary behaviour and PA habits in elementary school children.

\section{Material and Methods}

Baseline data from 1,103 (585 male, 518 female) first- and second-grade children ( $7.6 \pm 0.4$ years of age) participating in a school-based intervention programme (URMEL-ICE - Ulm Research on Metabolism, Exercise and Lifestyle in Children) in south-west Germany was used. Parents were provided written information prior to data collection and provided written consent. From children oral assent was obtained prior to data collection. The study protocol was approved by the University's institutional review board and by the Ministry of Education of the State of Baden-Wuerttemberg and is in accordance with the declaration of Helsinki.

Children's height and weight was measured at the endocrine out-patient clinic of Ulm Children's Hospital with the children wearing only underwear according to standard procedures. Height was measured to the nearest $0.1 \mathrm{~cm}$ using a stadiometer (Ulm Stadiometer, Busse Design, Ulm, Germany), and weight was measured to the nearest $0.1 \mathrm{~kg}$ using a balance beam scale (Seca, Hamburg, Germany). Subsequently BMI was calculated $\left(\mathrm{kg} / \mathrm{m}^{2}\right)$ and converted to BMI percentiles (BMIPCT) using German reference values [20]. Overweight/obesity was determined at a BMIPCT above the 90th percentile [20]. In addition, birth weight was 
Drenowatz et al.: Parental Characteristics Have a Larger Effect on Children's Health

Behaviour than Their Body Weight

obtained from birth records, and self-reported parental height $(\mathrm{cm})$ and weight $(\mathrm{kg})$ was used to calculate parental BMI $\left(\mathrm{kg} / \mathrm{m}^{2}\right)$. Parents were classified as normal-weight or overweight/obese using a cut point of 25 $\mathrm{kg} / \mathrm{m}^{2}[21]$.

Health behaviour and socio-economic background was assessed via parent questionnaire. Questions were based on the KiGGS survey, which assessed health behaviour in 18,000 German children and adolescents [22]. Specifically, parents were asked about their child's sport participation (club and non-club), time spent watching TV, their child's soft drink consumption as well as whether the child was having breakfast prior to going to school. TV time was used as a proxy for sedentary behaviour as this is the most prevalent sedentary behaviour in youth [23] and sport participation was used as an indicator of PA as this may be more accurately reported compared to unstructured habitual PA. Parents also reported their own time spent in front of the TV along with their participation in a sport club. Each question for parents and children had 5 categories. For sport participation and soft drink consumption, answer options were never, less than once/ week, 1-2 times/week, 3-5 times/week and almost daily. For time spent in front of the TV, categories consisted of never, roughly $30 \mathrm{~min} /$ day, 1-2 h/day, 3-4 h/day and more than $4 \mathrm{~h} /$ day. Parents were further asked to report their educational background and migration status, and children were considered as having a migration background if one of their parents was born outside Germany.

Descriptive characteristics were calculated and differences between boys and girls were examined via independent $\mathrm{t}$ test for BMIPCT and Mann Whitney U test for behavioural components. Sex-specific differences for parental BMI were examined via dependent $t$ test. The association between parental and children's body composition and health behaviour was initially explored via correlation analysis. The strength of the association was defined, for positive and negative trends, as strong ( $r>0.5)$, moderate $(0.5 \leq r \leq 0.3)$, or weak $(0.3<r<0.1)$ [24]. Subsequently, backwards multiple linear regression analysis was used to assess the association between parental BMI and health behaviour with children's BMIPCT. The examination of the association between various health behaviours and weight status occurred via multiple logistic regression. Cut points for sport participation were at least once a week for club sports or non-club sports. Similarly, soft drink consumption was dichotomized as consuming soft drinks more or less than once/week. TV viewing of more or less than $60 \mathrm{~min} /$ day was used to differentiate between high and low TV time, and parental education was dichotomized based on at least graduating from high school or not. Each analysis was performed for the total sample as well as separately for boys and girls. All statistics were performed in SPSS 19.0 with a statistical significance set at $\mathrm{p}<0.05$ using Bonferroni adjustment for multiple analyses.

\section{Results}

Descriptive characteristics, separated for boys and girls, are shown in table 1. Boys were significantly heavier at birth compared to girls. Boys also displayed higher body weight and height at measurement time, but there were no sex differences in BMIPCT. The prevalence of overweight/obesity, however, was higher in boys compared to girls. For health behaviour, only participation in club sports was significantly higher in boys compared to girls $(\mathrm{z}=-2.22$, $\mathrm{p}=0.03$ ), with no differences in TV time, soft drink consumption or having breakfast. There were no differences in parent BMI between boys and girls. Paternal BMI, however, was significantly higher compared to maternal BMI, which was also reflected by the prevalence of overweight/obesity. The overweight/obesity rate was twice as high in fathers compared to mothers.

The association between parental BMI and child BMIPCT as well as birth weight was significant (table 2). Parental behaviour and migration background also correlated significantly with the respective parental behaviour, except for habitual sport participation in boys (table 3). In general there was a stronger association between parental behaviours and the respective behaviour in girls compared to boys. Parental education was also significantly correlated with children's TV time and club sports, but not habitual sports. Despite being significant, correlations were generally weak, except for the association between parental and children's TV time and the association between migration background and club sport participation. 
Drenowatz et al.: Parental Characteristics Have a Larger Effect on Children's Health

Behaviour than Their Body Weight

Table 1. Descriptive characteristics ${ }^{\mathrm{a}}$

\begin{tabular}{lllll}
\hline & $\mathrm{N}$ & Total & Boys & Girls \\
\hline Child age, years & 1,103 & $7.6 \pm 0.5$ & $7.6 \pm 0.5$ & $7.5 \pm 0.4$ \\
Birth weight, g* $^{*}$ & 863 & $3,367 \pm 534$ & $3,411 \pm 530$ & $3,321 \pm 536$ \\
Height, cm* $^{*}$ Weight, kg* & 1,103 & $126.9 \pm 5.6$ & $127.6 \pm 5.5$ & $126.2 \pm 5.7$ \\
BMIPCT & 1,103 & $26.3 \pm 5.0$ & $26.8 \pm 5.1$ & $25.7 \pm 4.8$ \\
\% Overweight/obese & 1,103 & $49.6 \pm 28.9$ & $51.5 \pm 29.2$ & $47.6 \pm 28.5$ \\
\% Migration background & 1,103 & 11.7 & 13.9 & 9.2 \\
BMI mother, kg/m & 1,023 & 34.9 & 35.7 & 34.0 \\
\% Overweight/obese, mother & 1,067 & $24.1 \pm 4.3$ & $23.9 \pm 4.1$ & $24.2 \pm 4.6$ \\
BMI father, kg/m & 1,067 & 31.9 & 30.3 & 33.6 \\
\% Overweight/obese, father & 1,023 & $26.0 \pm 3.4$ & $26.0 \pm 3.4$ & $26.0 \pm 3.4$ \\
\hline
\end{tabular}

$\mathrm{N}=$ Sample size.

${ }^{a}$ Values are mean $\pm \mathrm{SD}$, unless prevalence is reported.

* Significant difference between boys and girls based on t-test $(\mathrm{p}<0.05)$.

${ }^{\dagger}$ Significant difference between boys and girls based on chi-square $(\mathrm{p}<0.05)$.

Table 2. Association between parental and child BMI ${ }^{\mathrm{a}}$

\begin{tabular}{llll}
\hline & $\mathrm{BMI}_{\text {mother }}$ & $\mathrm{BMI}_{\text {father }}$ & Birth weight \\
\hline Child BMIPCT & $0.200^{* *}$ & $0.234^{* *}$ & $0.150^{* *}$ \\
$\mathrm{BMI}_{\text {mother }}$ & & $0.217^{* *}$ & $0.140^{* *}$ \\
$\mathrm{BMI}_{\text {father }}$ & & & $0.094^{*}$ \\
\hline
\end{tabular}

aValues are Pearson correlation coefficients, adjusted for child's sex and age. ${ }^{*} \mathrm{p}<0.05 .{ }^{* *} \mathrm{p}<0.01$.

In the backwards linear regression only birth weight, parental BMI and the child's TV time remained as significant coefficients for BMIPCT after entering birth weight, parental BMI, parental education as well as the child having breakfast, soft drink consumption, TV time, club sport participation and habitual sport participation of the child (table 4). Results were similar in the sex-specific analyses but these variables explained only $10 \%$ ( $7 \%$ in girls and $16 \%$ in boys) of the children's BMIPCT. Further, it was shown that paternal BMI was more strongly associated with BMIPCT in boys, while maternal BMI was more strongly associated with BMIPCT in girls.

Higher parental BMI and watching TV for more than $60 \mathrm{~min} /$ day were also associated with increased odds for the child being overweight/obese (table 5). In addition, a lower odds ratio for overweight/obesity was observed with an increased participation of the child in club sports while habitual sport participation, soft drink consumption or having breakfast along with parental education and migration status were not shown to affect the odds of being overweight/obese. Similar to the results of the linear regression analysis, the model used for logistic regression explained only between 8 and 15\% of the variability in overweight/ obesity. Interestingly, parental BMI did not reach significance in the sex-specific analysis, and only club sport participation was associated with a reduction in the odds for being overweight/obese in boys and girls. In boys higher paternal education was also associated with reduced odds for being overweight/obese.

The odds for regular participation in club sports were significantly lower in overweight/ obese children, those having a migration background and children with regular soft drink 
Drenowatz et al.: Parental Characteristics Have a Larger Effect on Children's Health Behaviour than Their Body Weight

Table 3. Association between parental and child behaviour ${ }^{\mathrm{a}}$

\begin{tabular}{|c|c|c|c|c|c|c|c|c|c|}
\hline & \multicolumn{3}{|l|}{ TV time } & \multicolumn{3}{|l|}{ Club sport } & \multicolumn{3}{|c|}{ Habitual sports } \\
\hline & $\begin{array}{l}\text { boys } \\
(n=574)\end{array}$ & $\begin{array}{l}\text { girls } \\
(n=509)\end{array}$ & $\begin{array}{l}\text { total } \\
(n=1,083)\end{array}$ & $\begin{array}{l}\text { boys } \\
(n=556)\end{array}$ & $\begin{array}{l}\text { girls } \\
(n=483)\end{array}$ & $\begin{array}{l}\text { total } \\
(n=1,039)\end{array}$ & $\begin{array}{l}\text { boys } \\
(n=522)\end{array}$ & $\begin{array}{l}\text { girls } \\
(n=465)\end{array}$ & $\begin{array}{l}\text { total } \\
(\mathrm{n}=987)\end{array}$ \\
\hline $\begin{array}{l}\text { Behaviour }_{\text {mother }}{ }^{\dagger} \\
\quad(\mathrm{N}=1,085)\end{array}$ & $0.327^{* *}$ & $0.417^{* *}$ & $0.368^{* *}$ & $0.167^{* *}$ & $0.248^{* *}$ & $0.206^{* *}$ & 0.076 & $0.167^{* *}$ & $0.118^{* *}$ \\
\hline $\begin{array}{r}\text { Behaviour }_{\text {father }}{ }^{\dagger} \\
(\mathrm{N}=1,022)\end{array}$ & $0.305^{* *}$ & $0.367^{* *}$ & $0.335^{* *}$ & $0.136^{* *}$ & $0.152^{* *}$ & $0.147^{* *}$ & 0.024 & $0.133^{*}$ & $0.078^{*}$ \\
\hline $\begin{array}{l}\text { Migration background } \\
\qquad(\mathrm{N}=1,023)\end{array}$ & $0.304^{* *}$ & $0.269^{* *}$ & $0.288^{* *}$ & $-0.224^{*}$ & $-0.415^{* *}$ & $-0.314^{* *}$ & -0.067 & $-0.122^{*}$ & $-0.094^{*}$ \\
\hline $\begin{array}{l}\text { Education }_{\text {mother }} \\
(\mathrm{N}=1,080)\end{array}$ & $-0.200^{* *}$ & $-0.276^{* *}$ & $-0.238^{* *}$ & $0.159 * *$ & $0.241^{* *}$ & $0.199 * *$ & -0.003 & 0.079 & 0.036 \\
\hline $\begin{array}{l}\text { Education }_{\text {father }} \\
(\mathrm{N}=1,042)\end{array}$ & $-0.184^{* *}$ & $-0.220^{* *}$ & $-0.200^{* *}$ & $0.110^{*}$ & $0.106^{*}$ & $0.110^{* *}$ & -0.027 & 0.043 & 0.009 \\
\hline
\end{tabular}

aValues are Spearman correlation coefficients separately for boys and girls as well as the total sample.

${ }^{\dagger}$ Respective parental behaviour (i.e. parental activity, parental club sport, parental TV).

${ }^{*} \mathrm{p}<0.05 .{ }^{* *} \mathrm{p}<0.01$.

Table 4. Standardized coefficients and $\mathrm{R}^{2}$ for backwards linear regression analysis

\begin{tabular}{llllll}
\hline & Birth weight & $\mathrm{BMI}_{\text {mother }}$ & $\mathrm{BMI}_{\text {father }}$ & Child TV time & $\mathrm{R}^{2}$ \\
\hline BMIPCT $_{\text {total }}$ & $0.11^{* *}$ & $0.14^{* *}$ & $0.19^{* *}$ & $0.09^{*}$ & 0.10 \\
BMIPCT $_{\text {boys }}$ & 0.11 & $0.13^{*}$ & $0.31^{* *}$ & 0.08 & 0.16 \\
BMIPCT $_{\text {girls }}$ & 0.12 & $0.16^{*}$ & 0.08 & 0.08 & 0.07
\end{tabular}

Variables entered: birth weight, $\mathrm{BMI}_{\text {mother }}, \mathrm{BMI}_{\text {father }}$, Education mother $_{\text {, Education }}$ father, child heaving breakfast, child's soft drink consumption, child's club sport participation, child's habitual sports participation, child's TV time.

${ }^{*} \mathrm{p}<0.05{ }^{* *} \mathrm{p}<0.01$.

Table 5. Odds ratios with $95 \%$ CI for overweight/obesity in the total sample adjusted for sex and separately for boys and girls ${ }^{\mathrm{a}}$

\begin{tabular}{|c|c|c|c|}
\hline & Total $(95 \% \mathrm{CI})$ & Boys $(95 \% \mathrm{CI})$ & Girls (95\% CI) \\
\hline Overweight $_{\text {mother }}$ & $1.72(1.02 ; 2.89)$ & $1.43(0.70 ; 2.89)$ & $2.04(0.89 ; 4.72)$ \\
\hline Overweight $_{\text {father }}$ & $2.15(1.20 ; 3.87)$ & $2.19(0.99 ; 4.82)$ & $2.29(0.94 ; 5.57)$ \\
\hline High education $_{\text {mother }}$ & $1.00(0.55 ; 1.81)$ & $0.92(0.42 ; 2.00)$ & $1.30(0.49 ; 3.43)$ \\
\hline High education ${ }_{\text {father }}$ & $0.63(0.36 ; 1.10)$ & $0.44(0.20 ; 0.94)$ & $0.91(0.38 ; 2.17)$ \\
\hline Migration background & $1.23(0.69 ; 2.21)$ & $1.06(0.50 ; 2.25)$ & $1.56(0.59 ; 4.14)$ \\
\hline Regular breakfast $_{\text {child }}$ & $0.57(0.29 ; 1.12)$ & $0.40(0.16 ; 1.05)$ & $0.75(0.28 ; 2.01)$ \\
\hline Regular soft drink $\mathrm{child}_{\mathrm{c}}$ & $0.71(0.41 ; 1.20)$ & $0.54(0.27 ; 1.11)$ & $0.96(0.41 ; 2.25)$ \\
\hline High club sport $_{\text {child }}$ & $0.42(0.24 ; 0.75)$ & $0.40(0.18 ; 0.86)$ & $0.39(0.16 ; 0.95)$ \\
\hline High sport $_{\text {child }}$ & $1.19(0.68 ; 2.08)$ & $1.20(0.56 ; 2.60)$ & $1.18(0.50 ; 2.84)$ \\
\hline High TV time $_{\text {child }}$ & $1.76(1.02 ; 3.04)$ & $1.40(0.69 ; 2.86)$ & $2.31(0.97 ; 5.50)$ \\
\hline Correctly classified, \% & 88.0 & 86.1 & 89.9 \\
\hline Cox \& Snell $\mathrm{R}^{2}$-Nagelkerke $\mathrm{R}^{2}, \%$ & $7.9-15.3$ & $8.9-16.3$ & $8.1-16.8$ \\
\hline
\end{tabular}

${ }^{a}$ All variables were entered simultaneously in the model $(N=803)$. Significant results in italics. 
Drenowatz et al.: Parental Characteristics Have a Larger Effect on Children's Health Behaviour than Their Body Weight

Table 6. Odds ratios with $95 \%$ CI for children's regular club sport participation in the total sample adjusted for sex and separately for boys and girls ${ }^{\mathrm{a}}$

\begin{tabular}{|c|c|c|c|}
\hline & Total $(95 \% \mathrm{CI})$ & Boys $(95 \% \mathrm{CI})$ & Girls (95\% CI) \\
\hline Club sport $_{\text {mother }}$ & $1.88(1.08 ; 3.28)$ & $2.05(0.92 ; 4.56)$ & $1.76(0.78 ; 3.97)$ \\
\hline Club sport father & $1.73(1.04 ; 2.88)$ & $1.66(0.82 ; 3.34)$ & $1.73(0.80 ; 3.75)$ \\
\hline High education $_{\text {mother }}$ & $1.39(0.87 ; 2.20)$ & $1.31(0.68 ; 2.52)$ & $1.40(0.71 ; 2.75)$ \\
\hline High education $_{\text {father }}$ & $0.83(0.53 ; 1.29)$ & $0.71(0.37 ; 1.37)$ & $0.95(0.50 ; 1.83)$ \\
\hline Migration background & $0.25(0.16 ; 0.38)$ & $0.35(0.19 ; 0.62)$ & $0.17(0.09 ; 0.31)$ \\
\hline Regular breakfast $_{\text {child }}$ & $1.84(1.03 ; 3.27)$ & $1.08(0.45 ; 2.63)$ & $2.92(1.27 ; 6.72)$ \\
\hline Regular soft drink child & $0.57(0.38 ; 0.86)$ & $0.42(0.23 ; 0.76)$ & $0.80(0.43 ; 1.49)$ \\
\hline High sport $_{\text {child }}$ & $1.37(0.90 ; 2.09)$ & $1.31(0.72 ; 2.37)$ & $1.38(0.74 ; 2.57)$ \\
\hline High TV time $_{\text {child }}$ & $0.56(0.37 ; 0.85)$ & $0.46(0.26 ; 0.82)$ & $0.66(0.36 ; 1.23)$ \\
\hline Overweight $_{\text {child }}$ & $0.43(0.24 ; 0.77)$ & $0.38(0.18 ; 0.82)$ & $0.44(0.17 ; 1.11)$ \\
\hline Correctly classified, $\%$ & 72.2 & 78.2 & 69.6 \\
\hline Cox \& Snell $\mathrm{R}^{2}$ - Nagelkerke $\mathrm{R}^{2}, \%$ & $21.7-31.3$ & $18.3-26.9$ & $27.1-38.3$ \\
\hline
\end{tabular}

${ }^{a}$ All variables were entered simultaneously in the model $(\mathrm{N}=827)$. Significant results in italics.

Table 7. Odds ratios with $95 \%$ CI for children watching TV for more than $60 \mathrm{~min} /$ day in the total sample adjusted for sex and separately for boys and girls

\begin{tabular}{|c|c|c|c|}
\hline & Total $(95 \% \mathrm{CI})$ & Boys $(95 \% \mathrm{CI})$ & Girls $(95 \% \mathrm{CI})$ \\
\hline TV time mother $_{1}$ & $2.24(1.44 ; 3.49)$ & $2.03(1.09 ; 3.79)$ & $2.40(125 ; 4.64)$ \\
\hline TV time father & $2.33(1.45 ; 3.74)$ & $2.19(1.12 ; 4.29)$ & $2.56(1.28 ; 5.11)$ \\
\hline High education $_{\text {mother }}$ & $0.88(0.58 ; 1.35)$ & $0.80(0.44 ; 1.44)$ & $0.94(0.50 ; 1.75)$ \\
\hline High education $_{\text {father }}$ & $0.91(0.61 ; 1.34)$ & $0.86(0.49 ; 1.52)$ & $0.97(0.55 ; 1.69)$ \\
\hline Migration background & $1.97(1.29 ; 3.00)$ & $1.92(1.09 ; 3.37)$ & $2.12(1.09 ; 4.11)$ \\
\hline Regular breakfast $_{\text {child }}$ & $0.55(0.31 ; 0.96)$ & $0.55(0.24 ; 1.29)$ & $0.51(0.24 ; 1.10)$ \\
\hline Regular soft drink child & $1.68(1.17 ; 2.40)$ & $1.33(0.80 ; 2.19)$ & $2.02(1.19 ; 3.43)$ \\
\hline High sport $_{\text {child }}$ & $0.69(0.47 ; 1.01)$ & $0.66(0.39 ; 1.12)$ & $0.70(0.40 ; 1.23)$ \\
\hline High club sport $_{\text {child }}$ & $0.64(0.42 ; 0.97)$ & $0.47(0.26 ; 0.84)$ & $0.86(0.45 ; 1.63)$ \\
\hline Overweight $_{\text {child }}$ & $1.79(1.02 ; 3.16)$ & $1.39(0.66 ; 2.94)$ & $2.37(0.95 ; 5.89)$ \\
\hline Correctly classified, $\%$ & 69.1 & 70.0 & 70.7 \\
\hline Cox \& Snell $\mathrm{R}^{2}$ - Nagelkerke $\mathrm{R}^{2}, \%$ & $18.0-24.2$ & $16.8-22.5$ & $20.3-27.3$ \\
\hline
\end{tabular}

All variables were entered simultaneously in the model $(\mathrm{N}=825)$. Significant results in italics.

consumption and higher TV time (table 6). Parental club sport participation and the child having breakfast, on the other hand, were associated with increased odds for regular club sport participation. As was observed for overweight/obesity, parental club sport participation was no longer significantly associated with club spors participation of the child in the sex-specific analysis. In boys, being overweight/obese, high TV time, regular soft drink consumption and migration background were associated with reduced odds for regular club sport participation while in girls, only migration background reduced the odds for regular club sport participation. Having breakfast, however, was associated with an increased odds ratio for participation in club sports in girls.

The odds ratio of high TV time was reduced in children who reported regular club sport participation as well as in those having breakfast (table 7). Regular soft drink consumption, being overweight/obese, having a migration background as well as increased parental TV 
Drenowatz et al.: Parental Characteristics Have a Larger Effect on Children's Health Behaviour than Their Body Weight

time, on the other hand, increased the odds for high TV time in the children. Parental TV time above $60 \mathrm{~min}$ /day and migration background remained significant in the sex-specific analyses. Regular club sport participation, however, only remained significant in boys while in girls the association between regular soft drink consumption and high TV time remained significant.

\section{Discussion}

The focus of this study was to examine the association between parental and child characteristics in relation to health behaviour and body weight. Despite several significant associations, these results underline the complexity of influences on children's health behaviour as only a small part of the variability could be explained by the regression models. Nevertheless, parental weight as well as TV time and PA were associated with their children's body weight and respective behaviours. The lack of significance of parental characteristics in the sex-specific analyses for body weight and sport participation, except for parental education on boys' engagement in club sports, was probably due to the larger confidence intervals as a result of the reduced sample size. Results of this study further indicate that boys and girls are affected differently by certain constraints, which already has been addressed by Wisniewski and Chernausek [25], who argue that susceptibility to social, ethnic, genetic and environmental factors in relation to body weight may differ for boys and girls. Gustafson and Rhodes [13] also reported stronger relationships between PA levels of mothers and daughters as well as fathers and sons, but it was concluded that sex-specific associations between parental and children's health behaviour remain inconclusive [13, 25].

In the total sample, parental behaviour was significantly associated with the child's respective behaviour. As was shown in previous studies $[14,23,26]$, higher parental TV time was associated with increased odds for high TV time in children, and particularly shared TV time (i.e. parents and children watching TV together) has been shown to increase children's TV time [15]. Research on the association between PA levels of parents and their offspring, however, is less clear [13]. Garcia et al. [27] argued that particularly in younger children parents may function as exercise models, and higher activity levels have been shown in children whose parents were active [12]. Further, shared activities between parents and children have been suggested as possibly increasing children's PA levels [28]. In adolescents, on the other hand, no relationship between parental and children's activity levels was observed [14, 29], and van der Horst et al. [12] argued that even in children current evidence is insufficient to draw conclusions about the association between parental and children's PA. These authors suggested that parental support, rather than parental activity levels, affects children's PA [12]. Nevertheless, it is possible that physically active parents are more likely to provide support, such as transportation to facilities or sport events, as they put a higher value on PA [13].

In addition to positive associations with parental behaviour, migration background, but not parental education, reduced the likelihood of regular club sport participation while it increased the odds for higher TV time. Lange et al. [30] also reported increased TV time and lower club sport participation in migrant children independent of other indicators of socioeconomic status such as household income or parental education, and Sallis et al. [29] did not show any association between parent education and PA in children. Kantomaa et al. [31], on the other hand, did report a direct association between parent education and children's PA levels. It was, therefore, concluded that the evidence on the effect of parental education on children's PA remains inconclusive [12]. The association between parental education and children's TV time seems to be stronger [23] even though no direct influence of parental education and children's TV time has been shown in the present study. There was, however, 
Drenowatz et al.: Parental Characteristics Have a Larger Effect on Children's Health Behaviour than Their Body Weight

an inverse relationship between parental education and the parents' TV time (results not shown), and it could be argued that the effect of parental education may be mediated by higher parental TV time rather than directly influencing the child's TV time. Parenting style and rules for watching TV further affect TV habits of the children [32,33] and may also be associated with the parents' educational background. Another indicator of parental concern about their child's health could be providing breakfast, and children having breakfast has been associated with maternal education as well as family income and migration background [34]. The results of the present study also showed an association between having breakfast and increased club sport participation as well as reduced TV time. The increased health consciousness of these parents could have increased their likelihood of supporting PA or sport participation as well as limiting TV time.

The previously discussed parental behaviours may also reflect a certain general parenting style. Previous research identified four major parenting styles (authoritarian, authoritative, permissive and neglectful) using two dimensions of parental behaviour: responsiveness to and demandingness of the child [19]. Authoritarian parenting is characterized by strict rules, high demands in self-control and a low level of sensitivity. Authoritative parenting is characterized by encouragement to be independent, parental warmth and emotional support. Permissive parenting is associated with few rules or standards of behaviour, low demands for self-control and high sensitivity and warmth, whereas a neglectful parenting style is characterized by parents being emotionally distant from their children and little supervision. Although it is known that parenting style is significantly associated with health behaviour in children [16, 17], research regarding parenting styles and PA in children is rare. A crosssectional survey of 792 10- to 11-year-old UK children found permissive parenting as most related to children's PA [35]. In their research, using accelerometers to assess PA in children, permissive mothers were identified as more supportive in logistics than authoritative mothers. Similar results were found by Hennessy et al. [36] in a US study assessing 99 parentchild dyads. However, Schmitz et al. [37] identified girls of authoritative mothers to have the highest PA and lowest sedentary leisure habits. These equivocal findings can be due to the different measurements of parenting style and different age groups and emphasise the need for further research on this topic.

In addition to parental and environmental characteristics, the child's soft drink consumption as well as body weight status was associated with TV time and club sport participation. There was also an inverse association between club sport participation and TV while habitual sport participation did not affect either behaviour. Sallis et al. [38] did not report a significant relationship between TV time and PA either, and Lowry et al. [39] showed in highschool students that watching TV replaces light activities such as walking or playing rather than more vigorous activities like sport. The clinical relevance of TV time on body fatness has been argued as well, as children should have sufficient time for watching TV and engaging in sport and PA [40]. Nevertheless, higher TV time has been shown to affect dietary choices of children and mothers [41,42], and in the present study soft drink consumption doubled the odds for high TV time in girls. In boys no significant association between soft drinkconsumption and TV time was observed, but regular soft drink consumption was associated lower sport participation. In contrast to previous studies [43, 44], there was, however, no direct association between regular soft drink consumption and body weight.

The subjective assessment of health behaviour via parent questionnaire, however, needs to be considered when interpreting the findings of this study. Unfortunately, currently no validated questionnaire for the assessment of health behaviour in children is available but the questions used were based on a large-scale and well-published study [22]. Nevertheless, social desirability may be of concern as parents knew about the purpose of the following intervention, and their responses may have been biased to display a better health behaviour 
Drenowatz et al.: Parental Characteristics Have a Larger Effect on Children's Health Behaviour than Their Body Weight

of their children and themselves. Further, TV time was used as a proxy for sedentary behaviour. Even though, TV time has been considered to be the most common sedentary behaviour [23], the amount of time spent watching TV does not reflect total sedentary time [45]. Similarly, sport participation does not necessarily reflect total PA in either children or parents. Especially in younger children unstructured activities may contribute significantly to overall activity levels [46]. Sport participation, however, may be reported more accurately, and already in pre-schoolers a direct relationship between sport participation and habitual PA has been shown [47]. It should also be mentioned that the sample is not representative as only children whose teachers were willing to participate in a school-based intervention programme with parental involvement were addressed to enrol in the study.

Nevertheless, the results still provide valuable insights into the role of the home environment regarding children's health behaviour. It was shown that parents can serve as models for a healthy and active lifestyle in elementary school children. Another interesting finding was that parental characteristics explain more of the variability in children's health behaviour (i.e., TV time, sport participation) than the child's body weight. Parents support their children by facilitating access to facilities for sport and PA and function as a role model for a healthy lifestyle. Further, parenting style has been shown to impact and shape children's daily activities [16, 36, 37]. The involvement of parents in health-related interventions, therefore, seems to be crucial. Parents need to be reminded that they play a crucial role in the development of their children's behaviour. Differential effects of parenting style on children's health behaviour need to be communicated and implemented in parenteducation programmes. More research, however, is needed to identify key components contributing to an active and healthy lifestyle of children, which will help in the development of effective intervention strategies that will foster an active and healthy lifestyle of future generations.

\section{Acknowledgements}

The URMEL-ICE Study Group consists of: Swantje Berg, Susanne Brandstetter, Clemens Drenowatz, Christoph Galm, Jochen Klenk, Dmytro Prokopchuk, Anja Schreiber, Jürgen M. Steinacker, Ronald P. Steiner, Martin Wabitsch, Olivia Wartha.

URMEL-ICE was funded by the Baden-Württemberg Stiftung, Germany. The authors would like to acknowledge and thank all members of the study team for their excellent work and the teachers and pupils who participated in the study.

\section{Authors' Contributions}

CD analysed data and drafted the manuscript. NE conducted literature search and drafted the manuscript. OW and SB devised the reported study, collected data and revised the manuscript. JMS is principal investigator of the URMEL-ICE Study and revised the manuscript. All authors read and approved the final manuscript.

\section{Disclosure Statement}

The authors declare no conflict of interests. 
Drenowatz et al.: Parental Characteristics Have a Larger Effect on Children's Health Behaviour than Their Body Weight

\section{References}

$>1$

$>2$

Biro FM, Wien M: Childhood obesity and adult morbidities. Am J Clin Nutr 2010;91:1499S-1505S.

Weiss R, Dziura J, Burgert TS, Tamborlane WV, Taksali SE, Yeckel CW, Allen K, Lopes M, Savoye M, Morrison J, Sherwin RS, Caprio S: Obesity and the metabolic syndrome in children and adolescents. N Engl J Med 2004; 350:2362-2374.

3 World Health Organisation: World Health Report 2002: Reducing Risk - Promoting Healthy Life. Geneva, WHO Press, 2002.

4 De Niet JE, Naiman DI: Psychosocial aspects of childhood obesity. Minerva Pediatr 2011;63:491-505.

5 Naylor PJ, McKay HA: Prevention in the first place: schools a setting for action on physical inactivity. Br J Sports Med 2009;43:10-13.

6 Summerbell CD: The identification of effective programs to prevent and treat overweight preschool children. Obesity (Silver Spring) 2007;15:1341-1342.

7 Rhodes RE, Macdonald HM, McKay HA: Predicting physical activity intention and behaviour among children in a longitudinal sample. Soc Sci Med 2006;62:3146-3156.

-8 Pigeot I, Buck C, Herrmann D, Ahrens W: Overweight and obesity in children and adolescents. The worldwide situation (in German). Bundesgesundheitsbl 2010;53:653-665.

-9 Brown T, Summerbell C: Systematic review of school-based interventions that focus on changing dietary intake and physical activity levels to prevent childhood obesity: an update to the obesity guidance produced by the National Institute for Health and Clinical Excellence. Obes Rev 2009;10:110-141.

10 Zenzen W, Kridli S: Integrative review of school-based childhood obesity prevention programs. J Pediatr Health Care 2009;23:242-258.

11 Pyle S, Sharkey J, Yetter G, Felix E, Furlong M, Poston W: Fighting and epidemic: the role of schools in reducing childhood obesity. Psychol Sch 2006;43:361-376.

12 Van Der Horst K, Paw MJ, Twisk JW, Van Mechelen W: A brief review on correlates of physical activity and sedentariness in youth. Med Sci Sports Exerc 2007;39:1241-1250.

-13 Gustafson SL, Rhodes RE: Parental correlates of physical activity in children and early adolescents. Sports Med 2006;36:79-97.

14 Jago R, Fox KR, Page AS, Brockman R, Thompson JL: Parent and child physical activity and sedentary time: do active parents foster active children? BMC Public Health 2010;10:194.

15 Cui Z, Hardy LL, Dibley MJ, Bauman A: Temporal trends and recent correlates in sedentary behaviours in Chinese children. Int J Behav Nutr Phys Act 2011;8:93.

16 Kremers SPJ, Brug J, de Vries H, Engels RCME: Parenting style and adolescent fruit consumption. Appetite 2003;41:43-50.

$\checkmark 17$ Arredondo E, Elder J, Ayala G, Campbell N, Baquero B, Duerksen S: Is parenting style related to children's eating and physical activity in Latino families? Health Educ Res 2006;21:862-871.

$>18$ Baumrind D: Current patterns of parental authority. Dev Psychol Monogr 1971;4:101-103.

19 Maccoby E, Martin J: Socialization in the context of the family: parent-child interaction; in Hetherington E (ed): Handbook of Child Psychology: Socialization, Personality and Social Development. New York,Wiley, 1983, pp $1-101$.

20 Kromeyer-Hauschild K, Wabitsch M, Kunze D, Geller F, Geiß H, Hesse V, von Hippel A, Jaeger U, Johnson D, Korte W, K. Menner, G. Müller, J. M. Müller, A. Niemann-Pilatus, T. Remer, F. Schaefer, H.-U. Wittchen, S. Zabransky, K. Zellner, A. Ziegler, J. Hebebrand: Perzentile für den Body-mass-Index für das Kindes- und Jugendalter unter Heranziehung verschiedener deutscher Stichproben. Monatsschr Kinderheilkd 2001;149:807818.

-21 World Health Organisation: Physical Status: The Use and Interpretation of Anthropometry - Report of a WHO Expert Committee. Geneva, WHO Press, 1995.

-22 Kurth BM: The German Health Interview and Examination Survey for Children and Adolescents (KiGGS): an overview of its planning, implementation and results taking into account aspects of quality management (in German). Bundesgesundheitsbl 2007;50:533-546.

23 Gorely T, Marshall SJ, Biddle SJ: Couch kids: correlates of television viewing among youth. Int J Behav Med 2004;11:152-163.

24 Cohen J: Statistical Power Analysis for the Behavioral Sciences, 2nd ed. Hillsdale, L Erlbaum Associates, 1988

-25 Wisniewski AB, Chernausek SD: Gender in childhood obesity: family environment, hormones, and genes. Gend Med 2009;6:76-85.

26 Hume C, van der Horst K, Brug J, Salmon J, Oenema A: Understanding the correlates of adolescents' TV viewing: a social ecological approach. Int J Pediatr Obes 2010;5:161-168.

-27 Garcia AW, Broda MA, Frenn M, Coviak C, Pender NJ, Ronis DL: Gender and developmental differences in exercise beliefs among youth and prediction of their exercise behavior. J Sch Health 1995;65:213-219.

28 Moore LL, Lombardi DA, White MJ, Campbell JL, Oliveria SA, Ellison RC: Influence of parents' physical activity levels on activity levels of young children. J Pediatr 1991;118:215-219.

29 Sallis JF, Alcaraz JE, McKenzie TL, Hovell MF, Kolody B, Nader PR: Parental behavior in relation to physical activity and fitness in 9-year-old children. Am J Dis Child 1992;146:1383-1388. 
Drenowatz et al.: Parental Characteristics Have a Larger Effect on Children's Health Behaviour than Their Body Weight

30 Lange D, Plachta-Danielzik S, Landsberg B, Müller MJ: Social inequality, migration, and healthy environments as determinants of overweight of children and adolescents. Results of the Kiel Obesity Prevention Study (KOPS) (in German). Bundesgesundheitsbl 2010;53:707-715.

-31 Kantomaa MT, Tammelin TH, Näyhä S, Taanila AM: Adolescents' physical activity in relation to family income and parents' education. Prev Med 2007;44:410-415.

-32 Jago R, Davison KK, Thompson JL, Page AS, Brockman R, Fox KR: Parental sedentary restriction, maternal parenting style, and television viewing among 10- to 11-year-olds. Pediatrics 2011;128:e572-578.

33 van Zutphen M, Bell AC, Kremer PJ, Swinburn BA: Association between the family environment and television viewing in Australian children. J Paediatr Child Health 2007;43:458-463.

34 Dubois L, Girard M, Potvin Kent M: Breakfast eating and overweight in a pre-school population: is there a link? Public Health Nutr 2006;9:436-442.

35 Jago R, Davison KK, Brockman R, Page AS, Thompson JL, Fox KR: Parenting styles, parenting practices, and physical activity in 10- to 11-year olds. Prev Med 2011;52:44-47.

-36 Hennessy E, Hughes SO, Goldberg JP, Hyatt RR, Economos CD: Parent-child interactions and objectively measured child physical activity: a cross-sectional study. Int J Behav Nutr Phys Act 2010; 7:71.

-37 Schmitz KH, Lytle LA, Phillips GA, Murray DM, Birnbaum AS, Kubik MY: Psychosocial correlates of physical activity and sedentary leisure habits in young adolescents: the Teens Eating for Energy and Nutrition at School study. Prev Med 2002;34:266-278.

-38 Sallis JF, Prochaska JJ, Taylor WC: A review of correlates of physical activity of children and adolescents. Med Sci Sports Exerc 2000;32:963-975.

-39 Lowry R, Wechsler H, Galuska DA, Fulton JE, Kann L: Television viewing and its associations with overweight, sedentary lifestyle, and insufficient consumption of fruits and vegetables among US high school students: differences by race, ethnicity, and gender. J Sch Health 2002;72:413-421.

$\$ 40$ Marshall S, Biddle S, Gorely T, Cameron N, Murday E: Relationships between media use, body fatness and physical activity in children and youth: a meta-analysis. Int J Obes Relat Metab Disord 2004;28:1238-1246.

41 Coon KA, Tucker KL: Television and children's consumption patterns. A review of the literature. Minerva Pediatr 2002;54:423-436.

-42 Díaz-Ramírez G, Jiménez-Cruz A, Souto-Gallardo MeL, Bacardí-Gascón M: Effect of the exposure to TV food advertisements on the consumption of foods by mothers and children. J Pediatr Gastroenterol Nutr 2013;56: 86-88.

43 Libuda L, Kersting M: Soft drinks and body weight development in childhood: is there a relationship? Curr Opin Clin Nutr Metab Care 2009;12:596-600.

44 Malik VS, Schulze MB, Hu FB: Intake of sugar-sweetened beverages and weight gain: a systematic review. Am J Clin Nutr 2006;84:274-288.

45 Marshall S, Biddle S, Sallis J, McKenzie T, Conway T: Clustering of sedentary behaviours and physical activity among youth: a cross-national study. Pediatr Exerc Sci 2002;14:401-417.

-46 Zahner L, Muehlbauer T, Schmid M, Meyer U, Puder JJ, Kriemler S: Association of sports club participation with fitness and fatness in children. Med Sci Sports Exerc 2009;41:344-350.

47 Ebenegger V, Marques-Vidal P, Kriemler S, Nydegger A, Zahner L, Niederer I, Bürgi F, Puder JJ: Differences in aerobic fitness and lifestyle characteristics in preschoolers according to their weight status and sports club participation. Obes Facts 2012;5:23-33. 